\title{
Religião e Política no Brasil Contemporâneo: uma apresentação
}

\author{
Arlindo Souza Neto \\ Mísia Lins Reesink ${ }^{\mathrm{b}}$ \\ Paul Freston ${ }^{c}$
}

dos mais de 600 mil brasileiros
mortos pelo Covid-19.

Enquanto seres socioculturais não conseguimos escapar da nossa capacidade de produzir sentido. $\mathrm{O}$ atual contexto social demonstra que a religião e a política são duas categorias centrais no debate público contemporâneo. Mas não só isso, tanto a religião como a política são demarcadores socioculturais, uma vez que definem trajetórias, inspiram sociedades e, infelizmente, também criam contextos de morte, medo e, por vezes, terror. Não é preciso citarmos fatos históricos do passado para demonstrar tal enunciado, a história do tempo presente já é suficiente. Isto nos leva a indagar o porquê de, nas sociedades ocidentais, onde aparentemente a democracia até então parecia ter triunfado como sistema político promissor e civilizador, verificamos

a Doutor em Antropologia (UFPE). Professor Substituto do Instituto Federal do Rio Grande do Norte. Email: arlindosociologo@gmail.com.

b Professora do Departamento de Antropologia e Museologia e da Pós-Graduação em Antropologia (UFPE). Email: misia.reesink@ufpe.br.

c Catedrático (CIGI Chair in Religion and Politics in Global Context) na Balsillie School of International Affairs e na Wilfrid Laurier University, Waterloo, Ontário (Canadá).Email: pfreston@wlu.ca. 
contemporaneamente uma efervescência de conflitos entre as esferas políticas e religiosas?

Inspirados nesse tipo de problemática, ainda em 2019, realizouse na Universidade Federal de Pernambuco o I Seminário do Devir, com a temática 'Religião e Política', marcando o nascimento do Grupo de Pesquisa Devir: religião, contemporaneidade, morte, imagens. Grupo de pesquisa vinculado ao Programa de Pós-Graduação de Antropologia da UFPE. O evento teve como objetivo fomentar o debate antropológico por meio de mesas de debates e conferências, uma delas proferidas pelo professor Paul Freston, intitulada Bolsonaro e os Evangélicos: implicações políticas e religiosas, que tratou sobre a relação singular que se estabeleceu entre o então eleito presidente do Brasil e os grupos evangélicos apoiadores de sua candidatura e mandato.

Este dossiê, organizado por Paul Freston, Mísia Lins Reesink \& Arlindo J. Souza Neto, nasceu então em consequência daquele ambiente de discussão propositivas sobre a sociedade brasileira a partir das relações singulares entre religião e política, que desde 2010 se mostravam relevantes não apenas como fenômenos sociais localizados, mas sobretudo como consequências de um contexto de transformação global. Diante da positiva recepção, em 2020 realizou-se o II Seminário do Devir, dessa vez sob o tema 'Religião, democracia e morte no Brasil'. E em outubro de 2021, tivemos o III Seminário do Devir, com a temática 'O Brasil (des)cobertos: debates contemporâneos', no qual fechamos uma trilogia de seminários onde tínhamos o Brasil, a política e a religião como temas transversais e que objetivavam entender o que estava e ainda está acontecendo com as instituições e a esfera pública brasileiras.

Dessa maneira, entendemos que sem esses três momentos de debates e as contribuições de todos que participaram dos Seminários do Devir, este dossiê não teria existido. Em certo sentido, ele encerra um ciclo de debates, mas também entrega à comunidade acadêmica um pouco do que se está pensando antropologicamente sobre a contemporaneidade do nosso país. E diante dos atuais acontecimentos, a pu- 
blicação deste dossiê se mostrou urgente. Portanto, aqui, caros leitores, vocês encontrarão cinco artigos de pesquisadores e pesquisadoras de diferentes instituições brasileiras e estrangeiras, que objetivaram, cada qual a seu modo, contribuir para a compreensão da sociedade brasileira, a partir de recortes etnográficos, de suas experiências, pesquisas e problematizações.

Muito já se falou e escreveu sobre o fim da religião, vide as previsões dos teóricos do secularismo. Contudo, contemponeamente, a realidade tem mostrado que na esfera pública, ao longo das últimas décadas, os aspectos religiosos ganharam uma dimensão não esperada, especialmente na América Latina, mas não só. Os discursos religiosos foram e são utilizados com a finalidade de mobilizar o eleitorado, tanto para legitimar interesses particulares de grupos religiosos, tanto para deslegitimar adversários políticos que não tem muita inserção naquele campo religioso. E isso tem se tornado, em especial no Brasil, um aspecto corriqueiro.

Preocupações desse tipo já apareciam na década de 1990 aqui no Brasil , demonstrando a consolidação da arena política por determinados grupos religiosos. A literatura antropológica dos anos 90 abordou justamente o pontapé inicial do 'ativismo político evangélico', crescente naquele momento e consolidado hoje. Na primeira década deste século, as discussões entre o campo da religião e da política foi reaquecido, com a presença do fenômeno político-ideológico conservador influenciando o cenário eleitoral político no Brasil.

Como este é um tema contemporâneo e em ascensão, é compreensível que os fenômenos se apresentem de forma mais dinâmica, vide as críticas à democracia e à ascensão do fascismo no mundo. Este dossiê, ao reunir estudos que exploram a relação entre política e religião em diferentes arenas, traz análises que partem da temática da inserção e atuação de diferentes grupos religiosos na arena legislativa, da relação entre partidos políticos e igrejas, bem como das relações estabelecidas entre os grupos religiosos, as eleições e o uso das igrejas como catalizador de um eleitorado mais conservador e até certo ponto reacionário. 
O questionamento que se coloca como fio condutor deste dossiê parte do seguinte princípio: por qual ou quais meios os temas de grande repercussão política vêm impactando, nas últimas décadas, os pensamentos, os símbolos e valores, as práticas e ações, as alianças e as rivalidades nas esferas religiosas no contexto brasileiro, e vice-versa? Em última instância como política e religião, e religião e política se influenciam?

Outro aspecto relevante consiste justamente em entender uma incômoda incoerência no diálogo entre essas esferas. Em alguns momentos com certa aparência progressista, em outros, com severas reações conservadoras, nas duas últimas décadas, o Brasil tem vivido nesta maré, em certo momento indo rumo a transformações sociais significativas, com aparentes consolidações democráticas, e em outros, remando a favor da maré do conservadorismo. Vale destacar que tal movimento não está restrito apenas aos grupos religiosos, atualmente é um movimento generalizado na sociedade brasileira.

Quando entramos nessa seara discursiva, não estamos lidando apenas com uma relação político-religiosa ou religiosa-político, também estamos discutindo uma camada mais sutil desse fenômeno, ou seja, seu evidente aspecto político-ideológico. Arbitrariamente, podemos destacar o ano de 2013 como momento chave desse aspecto. Criou-se naquele momento um espaço favorável para vozes abertamente conservadoras, intolerantes e antidemocráticas. E isso definitivamente modificou a dinâmica da sociedade brasileira no que tange a sua composição político-ideológica.

Embora alguns possam argumentar que isto não seja uma novidade - e eles estão certos, vide a história do Brasil, esta camada mais sutil da discussão refere-se não apenas à arena pública de debates, mas sim às críticas as prescrições da Constituição Federal de 1988, a qual visa garantir direitos humanos inalienáveis. O que observamos na sociedade brasileira contemporânea é o adensamento da relação entre religião, especificamente das interpretações religiosas no que tange à noção de pessoa e à construção da ideia do 'outro', e o aviltamento da dignidade humana. 
Por isso, se mostra urgente compreender antropologicamente tais manifestações. Assim, para melhor sistematizar a discussão podemos observar quatro grandes movimentos dessa relação entre religião e política no Brasil: (1) acerca da laicidade do Estado e sua relação com as religiões na esfera pública; (2) a participação de grupos religiosos na arena política; (3) a atuação político-eleitoral de grupos religiosos; e, (4) o conservadorismo religioso atuando nas esferas jurídica e legislativa, bem como no ativismo político-partidários influenciando as políticas públicas.

De certo modo, os trabalhos aqui reunidos pensam esse movimento reflexivo descrito acima. O texto de Emanoel F. da Silva \& Emerson J. S. da Silveira, intitulado 'A Bíblia É o Nosso Regimento': debate parlamentar, liberdade de crença e democracia-liberal representativa problematizam a razão de legislar sobre crimes de intolerância religiosa. Para isso, Silva \& Silveira propõem uma análise das relações entre religião e política no Brasil contemporâneo a partir dos usos da ideia de liberdade de crença por parlamentares religiosos. Tendo por base a tramitação do Projeto de Lei 578/2019, na Assembleia Legislativa do Ceará, versando sobre a punição de crimes de intolerância religiosa, sofreu veemente oposição por parte de deputados evangélicos, os quais argumentaram que tal projeto de lei 'ameaça à Igreja de Jesus'. O projeto foi criticado sob o argumento da 'liberdade de crença'.

Silva \& Silveira, então, realizam em seu texto, a partir de uma perspectiva qualitativa, uma relevante revisão bibliográfica combinada a uma análise discursiva dos conceitos de 'cidadania religiosa' e de 'democracia agonística', a fim de problematizar a hipótese de que no campo político-ideológico, os atores religiosos desenvolvem toda uma argumentação teológica para impedir que determinados projetos avancem nas discussões legislativas com base na premissa de 'ameaça à fé'. Tal manobra legitima, segundo Silva \& Silveira, o código moral-religioso, mesmo a arena estando nos limites da democracia representativa. É interessante observar esse tipo de movimentação, uma vez que reavaliar como são postos na sociedade brasileira os limites à laicidade 
do Estado pela atuação de parlamentares, por exemplo, não apenas aumenta o campo heurístico de análise, mas sobretudo demonstra como se dão certas construções narrativas para legitimar e defender os interesses de determinadas instituições religiosas, que em última instância são a raison d'être dos mandatos de certos parlamentares brasileiros.

No artigo de Ole Jakob Løland, intitulado As Condições Politicas e os Fundamentos Teológicos da Nova Direita Cristã no Brasil, são desenhadas algumas argumentações que evidenciam a dinâmica entre religião e política no Brasil contemporâneo. Estabelecendo um diálogo entre o campo da Teologia e das Ciências Sociais, Løland parte da vitória eleitoral de Jair Messias Bolsonaro em 2018, apoiado por quase 70\% dos evangélicos e cerca de $50 \%$ dos católicos brasileiros, para explorar algumas das teologias políticas e influentes que são disseminadas por alguns dos aliados religiosos de Bolsonaro. Para organizar sua argumentação Løland sistematizou três tipologias teológicas. A primeira denominada de sobrenaturalismo neoliberal, a segunda de dualismo apocalíptico e a terceira de neoconservadorismo católico.

Além disso, Løland argumenta que a Nova Direita Cristã no Brasil é comparável ao fenômeno 'the Christian Right', típico dos Estados Unidos, devido às semelhanças das condições políticas e as bandeiras morais levantadas então. Com o artigo de Løland, fica mais evidente que a ascensão de Bolsonaro e a virada para a direita na política brasileira podem ser em parte entendidas como um efeito dessa nova aliança política, a qual foi legitimado, segundo o autor, com base em três forças cristãs politicamente conservadoras: o pentecostalismo tradicional, o neopentecostalismo e o catolicismo neoconservador.

Essa argumentação de Løland pode ser observada nas descrições presentes no texto de Mariana Azevedo \& Roberto Efrem Filho, intitulado A Maioria Perseguida: religião, ciência e democracia na audiência pública sobre aborto no STF. Os autores buscaram compreender as atuais configurações da religião na controvérsia pública sobre a descriminalização do aborto no Brasil. Para tanto, voltaram-se sua análise para a audiência pública realizada no Supremo Tribunal Federal como parte 
do processamento da Arguição de Descumprimento de Preceito Fundamental (ADPF) 442, mas sobretudo às vinte e quatro exposições realizadas por representantes de entidades autodenominadas religiosas e pelos demais expositores que citaram a religião para a construção de seus argumentos contrários ou favoráveis à descriminalização do aborto até a $12^{\mathrm{a}}$ semana de gestação.

Segundo Azevedo \& Efrem Filho, tais exposições oportunizaram intensas disputas, entendidas pelos autores como interiores a uma linguagem de direitos em torno do conhecimento científico de diferentes concepções de democracia e da própria religião. Nessas disputas, atores religiosos não raro se identificam como uma maioria perseguida pelos 'excessos ideológicos' característicos de um 'ativismo judicial' protagonizado pelos ministros do Supremo Tribunal Federal (STF), mas não só, e contrário ao que seria a 'moral' do povo brasileiro. Em certo sentido, o texto de Azevedo e Efrem Filho acaba evidenciando a sistematização proposta por Løland em plena ação na sociedade brasileira, onde a conservadorismo com base em argumentos teológicos se digladiam com os argumentos jurídicos e científicos.

Já no texto de Michel Gherman \& Misha Klein, intitulado Aquela Noite: o lugar da Israel imaginária na nova direita brasileira, encontramos uma reflexão sobre o significado dos símbolos judaicos e sionistas no contexto político contemporâneo do Brasil. Gherman e Klein buscaram explorar os significados do aparecimento destes símbolos em manifestações da 'Nova Direita' brasileira, a fim de entenderem as relações de simbólicas com grupos conservadores no país. Além disso, o texto também traz à tona um aspecto importante de ser tratado que se refere à mudança de significado de 'raça' judaica no Brasil após a realização da Conferência de Durban em 2001 e suas consequências para a população judaica residente no país. Uma das consequências mais importantes sendo a possibilidade da instauração de um 'judaísmo bolsonarista' que não reconhece ou desvincula o bolsonarismo de suas raízes nazistas e fascistas, provocando uma cisão na comunidade judaica brasileira. 
Por fim, mas não menos importante, temos o texto de Marcia Contins, intitulado Da Aflição aos Direitos: reflexões sobre contextos religiosos e os discursos de 'ação afirmativa', no qual a autora reverbera, a partir de sua trajetória, enquanto pesquisadora das religiões de matrizes africanas no Brasil em áreas urbanas, um aspecto que há muito vem aparecendo em seus escritos: as transformações no campo religioso, em especial no Rio de Janeiro, e sua repercussão na formação de novas subjetividades e na apropriação discursiva das 'ações afirmativas' por parte dos atores desse campo.

Em seu artigo, Contins analisou de que modo as transformações sociais e internas ao campo afro-brasileiro repercutem na autoconsciência dos atores situados nesse campo religioso, especialmente no que se refere a sua presença no espaço público. Como base de sua argumentação está a premissa de que no campo dos discursos e das políticas de 'ação afirmativa', os atores, deslocando o tema religioso das aflições, apresentam-se como 'sujeitos de direito', com um discurso pautado por reivindicações sociais e políticas, o qual evidencia que ninguém está livre da relação política e religião, religião e política.

Os editores deste dossiê, consideramos que este pequeno conjunto de textos, aqui organizados, significa uma contribuição importante para a reflexão e o conhecimento do atual contexto político-religioso pelo qual passa o Brasil.

Nota:

${ }^{1}$ Ver, por exemplo, P. Freston (1993).

Referência:

FRESTON, Paul. 1993. Protestantismo e política no Brasil: da constituinte ao impeachment. Tese de Doutorado. Campinas: UNICAMP. 